\title{
IUFOST2006/710 Food Safety Approach into Romanian Bread-making industry within the Context of EU Integration
}

\author{
A. Sîrbu \\ Constantin Brancoveanu University, FMMAE Valcea, 39 Nicolae Balcescu Ave., 240210 Ramnicu Valcea, \\ Romania \\ asirbu@yahoo.com
}

The interests on food safety have strengthened globally in the last decade, and the Romanian concerns were oriented, too. The national policy and regulations have been partially adapted to EU ones, and the capacitybuilding have started to be reinforced. Food safety became a hot topic on the food chain and Romanian industry was forced to face with those food safety requirements, expressed by regulations and standards.

Baked products consumption in Romania is higher - approximate double than other EU countries, and bread is the staple foot of Romania. For those reasons the bakery is one of the main food sectors (after meat and dairy industry) about which Romanian authorities have focused on. In that work there are highline specific features of food safety approach into Romanian bread-making industry. For HACCP system implementation are used SR DS 3027 E: 2002 and recently SR ISO 22000: 2005. Because of specific features on management and resources, there are major differences between small- size and large-scale bakery companies' outlooks in order to accomplish the food safety requirements. For many Romanian organizations, the concerns on food safety approach focused more on economical reasons and legal constrains than on public health benefit.

Like general aspects, there are economical problems regarding food safety approach and HACCP system implementation in bakery field, especially for SMEs', and many specific issues are generated by technical ones. From raw materials, processing and bread trade, as well as food control on the entire food chain sides many difficulties have arisen and some of those are developed in that paper. In another order, the rules' interpretation is still an obstacle for a mutual agreement between control bodies and food organizations, in view of a suitable implementation. With all those problems, an improvement of Romanian bread-making background in order to achieve the food safety requirements were registered from one year to another in the last ones. 